\title{
Silica Gel Supported Hydrophobic Ionic Liquid for Selective Extraction and Determination of Coumarin
}

\author{
Hadi M. Marwani ${ }^{1,2^{*}}$, Esraa M. Bakhsh ${ }^{1}$ \\ ${ }^{1}$ Department of Chemistry, Faculty of Science, King Abdulaziz University, Jeddah, Saudi Arabia \\ ${ }^{2}$ Center of Excellence for Advanced Materials Research, King Abdulaziz University, Jeddah, Saudi Arabia \\ Email: "hmarwani@kau.edu.sa
}

Received November 2, 2012; revised December 3, 2012; accepted December 18, 2012

\begin{abstract}
In this study, a modified silica gel surface with a hydrophobic ionic liquid (SG-1,10-PhenanNTf ${ }_{2}$ ) was used as an adsorbent for a selective extraction of coumarin prior to its determination by use of high performance liquid chromatography. Results demonstrated that SG-1,10-PhenanNTf 2 phase had a good adsorption capacity up to $85.29 \mathrm{mg} \cdot \mathrm{g}^{-1}$, high selectivity, good site accessibility and fast binding kinetics toward coumarin. The adsorption capacity for coumarin was improved by $62.33 \%$ with the SG-1,10-PhenanNTf ${ }_{2}$ phase as compared to activated silica gel. Adsorption isotherm data displayed that the adsorption process was mainly monolayer on a homogeneous adsorbent surface, confirming the validity of Langmuir adsorption isotherm model. The adsorption of coumarin on the SG-1,10-PhenanNTf ${ }_{2}$ phase was accomplished after only 60 min contact time. Results of kinetic models showed that the adsorption of coumarin on the SG-1,10-PhenanNTf 2 phase obeyed a pseudo second-order kinetic model. Finally, the efficiency of this methodology was confirmed by applying it to real water samples.
\end{abstract}

Keywords: Coumarin; Silica Gel; Uptake Capacity; Ionic Liquid; Batch Method

\section{Introduction}

Most of organic compounds have a limited solubility in water and as a result they exist only at ultra concentrations level. Direct determination of these compounds in different kinds of environmental samples is often a challenging task for analysts. Also, it may cause serious interferences during measurement because of the lack of sensitivity and selectivity of analytical methods. In addition, a clean-up step is often required because of high levels of other components usually accompany the target compound. Therefore, an efficient extraction step is often necessary for accurate, sensitive and interference-free determination. There are several extraction techniques, including liquid-liquid extraction [1,2], ion exchange [3], accelerated solvent extraction [4], cloud point extraction [5], supercritical fluid extraction [6] and solid phase extraction (SPE) $[7,8]$. However, SPE is one of the most widely and commonly used techniques for pre-treatment of environmental samples. This is attributed to its advantages of higher enrichment factor, absence of emulsion, safety with respect to hazardous samples, minimal costs due to low consumption of organic solvent, environment friendly, flexibility and easier incorporation into automated analytical techniques [9]. Moreover, several ad-

\footnotetext{
Corresponding author.
}

sorbents have been used as solid phase extractors, such as alumina [10], activated carbon [11], carbon nanotubes [8], cellulose [12], C18 [13], resins [14], molecular imprinted polymers [15] and silica gel [16-19]. Silica gel (SG) is one of the most widely used adsorbent due its simple handling, high surface area, fast kinetics, mechanical, thermal and chemical stability under various conditions [20]. It is also an efficient adsorbent for the extraction and separation of various types of compounds. However, adsorption of organic compounds at ultra-trace levels by SG alone cannot be directly achieved, and it is often necessary to modify the SG with chelating agents for enhancing its selectivity and capability for monitoring organic compounds in the environment.

Ionic liquids (ILs) have recently gained recognition as in different chemical fields due to their unique properties and their potential as greener solvent for many organic, inorganic, and polymeric substances as compared to the traditional organic solvents which are toxic and environmentally harmful [21,22]. Because of their unique properties, the applications of ILs have been expanded in various fields, such as solvent extractions [23], liquid-liquid extractions [24,25], enzymatic reactions [26], pharmaceutical studies [27], electrochemical studies [28], dye-sensitized solar cells and batteries [29,30], gas sensors for detection of polar and non-polar organic vapors 
[31], supported electrolytes in capillary electrophoresis, mobile phase additives in liquid chromatography and stationary phases in gas-liquid chromatography $[32,33]$. In addition, ILs can be physically adsorbed onto solid phase extractors surface by electrostatic interaction due to their high viscosities and negligible vapor pressure [34]. Several studies have described the efficiency of ionic liquid functionalized silica as an adsorbent for selective extraction of organic compounds $[35,36]$.

However, finding a selective chelating agent capable to selectively bind to the target compound is one of the problems often encountered in applications of ILs for organic compounds extraction from various matrices using different extraction methods. In accordance, the present study was purposed to explore the analytical potential of SG-1,10-PhenanNTf $f_{2}$ phase as an adsorbent on the selectivity and adsorption capacity of coumarin prior to its determination by high performance liquid chromatography (HPLC). The SG-1,10-PhenanNTf ${ }_{2}$ phase has already been proven to be an effective adsorbent for selective extraction of $\mathrm{Pb}$ (II) prior to its determination by use of inductively coupled plasma-optical emission spectrometry in our previous study [37]. The preparation of the adsorbent was accomplished by combining a hybridization process of the hydrophobic ionic liquid characters with high adsorption efficiency and surface area of SG. The resulted SG-1,10-PhenanNTf $f_{2}$ adsorbent was characterized by use of Fourier transform infrared (FT-IR) spectroscopy and scanning electron microscope (SEM). The selectivity of SG-1,10-PhenanNTf $f_{2}$ toward several organic compounds was investigated. In addition, the effect of different factors controlling the maximum uptake of coumarin on the SG-1,10-PhenanNTf $f_{2}$ phase was studied under batch conditions. Langmuir classical adsorption isotherm model accurately represented the results of coumarin adsorption isotherm. Results of the kinetic analysis also demonstrated that the adsorption process obeyed a pseudo second-order adsorption model. Furthermore, the efficiency of this methodology was validated by applying it to real water samples.

\section{Experimental}

\subsection{Chemicals and Reagents}

1,10-Phenanthroline monohydrate hydrochloride $(1,10$ PhenanCl), bis(trifluoromethane)sulfonimide lithium $\left(\mathrm{LiNTf}_{2}\right)$, coumarin, 4-chloroaniline, flavone, 9-fluorenone, isatin, naphthalene, phenanthrene, phenazine, phenazone and HPLC grade acetonitrile (ACN) were purchased from Sigma-Aldrich (Milwaukee, WI, USA). SG $\left(\mathrm{SiO}_{2}\right.$, particle size $\left.10-20 \mathrm{~nm}\right)$ with purity of $99.5 \%$ was also obtained from Sigma-Aldrich. All reagents used were of analytical and spectral purity grade. Doubly dis- tilled deionized water was used throughout experimental studies.

\subsection{Preparation of the SG-1,10-PhenanNTf ${ }_{2}$ Adsorbent}

SG-1,10-PhenanNTf ${ }_{2}$, as shown in Scheme 1, was synthesized according to previously reported procedures by Marwani [37,38]. Specifically, the SG-1,10-PhenanNTf ${ }_{2}$ phase was prepared based on the physical adsorption of hydrophobic ionic liquid $\left(1,10-\right.$ PhenanNTf $\left._{2}\right)$ on the activated SG surface. An amount of $5 \mathrm{~g}$ activated SG was suspended in $100 \mathrm{~mL}$ toluene, and 1g 1,10-PhenanNTf ${ }_{2}$ was completely dissolved by warming in $50 \mathrm{~mL}$ toluene and added to the activated SG suspension. The reaction mixture was heated and stirred at $60^{\circ} \mathrm{C}$ for $12 \mathrm{~h}$. The modified SG-1,10-PhenanNTf ${ }_{2}$ phase was filtered and washed with $50 \mathrm{~mL}$ toluene on three portions followed by ethanol and diethyl ether. Then, the SG-1,10-PhenanNTf $\mathrm{N}_{2}$ adsorbent was dried in an oven at $80^{\circ} \mathrm{C}$ for $5 \mathrm{~h}$ and kept in a desiccator for further use. The concentration of 1,10-PhenanNTf ${ }_{2}$ ionic liquid on the surface of activated SG was determined to be $0.25 \mathrm{mmolg}^{-1}$ based on thermal desorption method [37].

\subsection{Batch Method Procedure}

All stock solutions were prepared in ACN (HPLC grade) and stored in the dark at $4{ }^{\circ} \mathrm{C}$. To examine the selectivity of SG-1,10-PhenanNTf ${ }_{2}$ toward different organic compounds, 5 and $50 \mathrm{mg} \cdot \mathrm{L}^{-1}$ standard solutions of coumarin, 4-chloroaniline, flavone, 9-fluorenone, isatin, naphthalene, phenanthrene, phenazine and phenazone were prepared by adding appropriate amounts of each stock solution. All standard solutions were individually mixed with $20 \mathrm{mg} \mathrm{SG}-1,10-$ PhenanNTf $_{2}$. For the study of coumarin adsorption capacity under batch conditions, standard solutions of $5,10,20,30,40,50,60,80,100,125,150$ and $200 \mathrm{mg} \cdot \mathrm{L}^{-1}$ coumarin were prepared as above and individually mixed with $20 \mathrm{mg}$ SG-1,10-PhenanNTf $\mathrm{F}_{2}$. In addition, the effect of shaking time on the coumarin adsorption capacity was investigated under the same batch

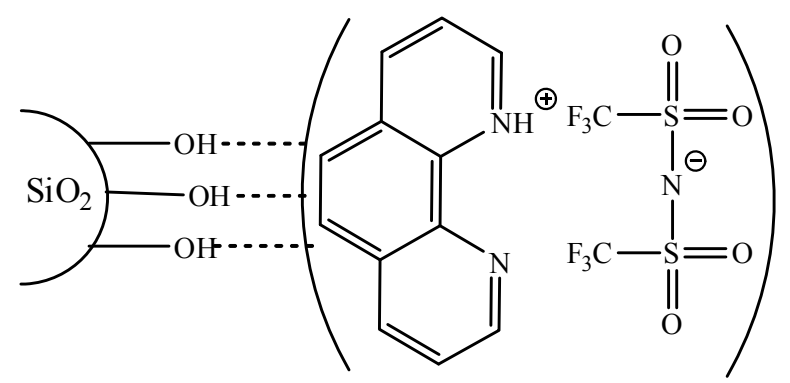

Scheme 1. Chemical structure of the SG-1,10-PhenanNTf ${ }_{2}$ phase [37]. 
conditions but at different equilibrium periods, including $2.5,5,10,20,30,40,50$ and $60 \mathrm{~min}$. The concentration of each substrate solution was monitored by HPLC and calculated from the calibration plot of the peak area as a function of the concentration. For the study of the effect of matrix interferences on the extraction of coumarin by SG-1,10-PhenanNTf 2 , a standard solution of $150 \mathrm{mg} \cdot \mathrm{L}^{-1}$ coumarin, flavone, naphthalene and phenanthrene was prepared and mixed with $20 \mathrm{mg}$ SG-1,10-PhenanNTf 2 . The mixture was then mechanically shaken for $1 \mathrm{~h}$ at room temperature.

\subsection{Methods}

SEM studies were performed before and after modification of the SG phase by use of a field emission-scanning electron microscope (FE-SEM, QUANT FEG 450, Amsterdam, Netherlands). The microscope was operated at an accelerating voltage of $15 \mathrm{kV}$. HPLC measurements were acquired by use of an Agilent Technologies 1200 Series, USA. The chromatographic system consisted of a model G1361A pump and G1315B DAD UV detector. All separations were achieved on an analytical reversed phase column (ZORBAX ODS, $4.6 \times 150 \mathrm{~nm}$ ) with a flow rate of $1 \mathrm{~mL} \cdot \mathrm{min}^{-1}$, and the volume of sample injection was $20 \mu \mathrm{L}$. An isocratic elution was established with a mobile phase composition of $60 \% \mathrm{ACN}$ and $40 \%$ water at room temperature. The UV detector was operated at wavelengths of $198 \mathrm{~nm}$ for 4-chloroaniline, $252 \mathrm{~nm}$ for 9-fluorenone, $215 \mathrm{~nm}$ for naphthalene, $251 \mathrm{~nm}$ for phenanthrene, $244 \mathrm{~nm}$ for phenazine, $243 \mathrm{~nm}$ for isatin and phenazone and $203 \mathrm{~nm}$ for coumarin and flavone.

\section{Results and Discussion}

\subsection{Characterization of SG-1,10-PhenanNTf $f_{2}$ Phase}

FT-IR spectra confirmed the formation of the physically modified phase (SG-1,10-PhenanNTf $f_{2}$ ) as previously reported elsewhere [37]. In addition, SEM images were taken for activated SG and SG-1,10-PhenanNTf 2 in order to further confirm the formation of the physically modified SG-1,10-PhenanNTf ${ }_{2}$ adsorbent (Figures 1(a) and (b)). As shown in Figure 1(b), the immobilization of hydrophobic ionic liquid (1,10-PhenanNTf 2 ) on the surface of activated SG resulted in a pronounced and characterized change of the surface morphology of activated SG. It can be noticed that $1,10-$ PhenanNTf $_{2}$ collected activated SG particles in aggregate forms that are completely covered with it. In addition, the SEM image given in Figure 1(b) of the modified SG-1,10-PhenanNTf ${ }_{2}$ adsorbent clearly displays the particles as individually distributed in uniform and homogeneous shapes as compared with that of activated SG (Figure 1(a)).

\subsection{Selectivity Study}

For the study of the selectivity of the SG-1,10-PhenanNTf $f_{2}$ phase toward different organic compounds, desired concentrations of 5 and $50 \mathrm{mg} \cdot \mathrm{L}^{-1}$ coumarin, 4chloroaniline, flavone, 9-fluorenone, isatin, naphthalene, phenanthrene, phenazine and phenazone were chosen. All solutions were individually mixed with $20 \mathrm{mg}$ SG1,10-PhenanNTf 2 . As can be observed in Table 1, the distribution coefficient value and amount of each compound adsorbed per unit mass of the SG-1,10-PhenanNTf ${ }_{2}$ adsorbent at equilibrium $\left(q_{e}, \mathrm{mg} \cdot \mathrm{g}^{-1}\right)$ were calculated in these competitive experiments. The distribution coefficient $\left(K_{d}, \mathrm{~mL} \cdot \mathrm{g}^{-1}\right)$ value corresponds to the character of a compound adsorbed by an adsorbent and can be calculated from the following equation [39]:

$$
K_{d}=\left[\left(C_{i}-C_{e}\right) / C_{e}\right] \times(V / m)
$$

where $C_{i}$ and $C_{e}$ are initial and final concentrations $\left(\mathrm{mg} \cdot \mathrm{L}^{-1}\right)$, respectively, $V$ refers to the volume of solution $(\mathrm{mL})$, and $\mathrm{m}$ is the mass of adsorbent $(\mathrm{g})$. The final concentrations $\left(C_{e}\right)$ were determined based on the calibration plot of the peak area as a function of the concentration. The results displayed that coumarin had the greatest $K_{d}$ value up to 21476.27 and $4004.12 \mathrm{~mL}^{-1}$ for 5 and 50 $\mathrm{mg} \cdot \mathrm{L}^{-1}$, respectively, on the SG-1,10-PhenanNTf ${ }_{2}$ adsorbent as compared with other compounds examined on SG-1,10-PhenanNTf 2 . Therefore, the results of selectivity study indicated that SG-1,10-PhenanNTf ${ }_{2}$ was most selective for coumarin over all other compounds, including 4-chloroaniline, flavone, 9-fluorenone, isatin, naphthalene, phenanthrene, phenazine and phenazone. The partial ionic charges produced on the surface of activated SG and incorporated donor atoms $(\mathrm{O}, \mathrm{N}$ and $\mathrm{S})$ presented in SG-1,10-PhenanNTf 2 , as a result of immobilization of the 1,10-PhenanNTf $\mathrm{N}_{2}$ ionic liquid on the activated SG, strongly attained the selective adsorption of SG-1,10PhenanNTf $f_{2}$ toward coumarin. Thus, the highest selectivity of SG-1,10-PhenanNTf ${ }_{2}$ toward coumarin may be attributed to an electrostatic attraction, physical, mechanism between SG-1,10-PhenanNTf ${ }_{2}$ and coumarin (Scheme 2).

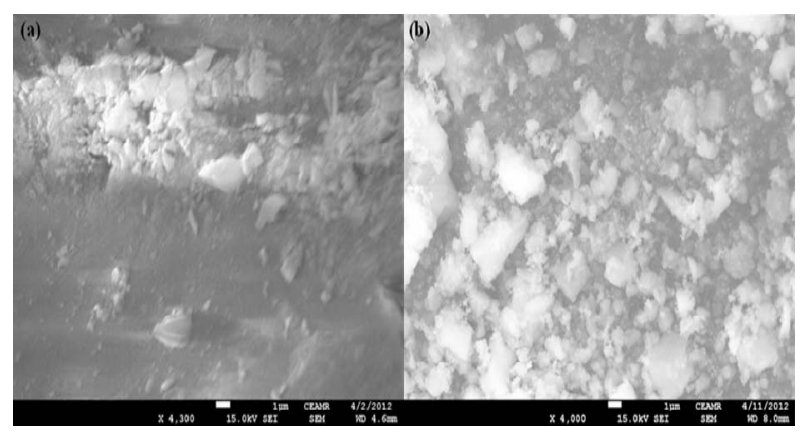

Figure 1. SEM images of (a) activated SG and (b) SG-1, 10-PhenanNTf $f_{2}$ phase. 


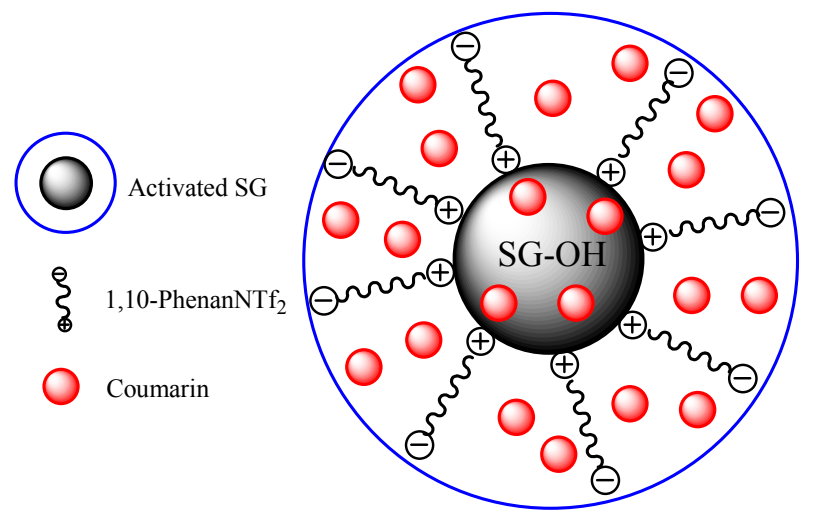

Scheme 2. Interaction mechanism between SG-1,10-PhenanNTf $f_{2}$ and coumarin.

Table 1. Selectivity study of $20 \mathrm{mg}$ SG-1,10-PhenanNTf toward different compounds.

\begin{tabular}{cccc}
\hline Compound & $\begin{array}{c}\text { Concentration } \\
\left(\mathrm{mg} \cdot \mathrm{L}^{-1}\right)\end{array}$ & $\begin{array}{c}q_{e} \\
\left(\mathrm{mg} \cdot \mathrm{g}^{-1}\right)\end{array}$ & $\begin{array}{c}K_{d} \\
\left(\mathrm{~mL} \cdot \mathrm{g}^{-1}\right)\end{array}$ \\
\hline Coumarin & 5 & 5.91 & 21476.27 \\
Flavone & 50 & 47.63 & 4004.12 \\
& 5 & 0.57 & 124.63 \\
Isatin & 50 & 2.25 & 46.73 \\
Phenazone & 5 & 0.01 & 2.51 \\
& 50 & 4.23 & 90.65 \\
Phenazine & 5 & 0.01 & 2.51 \\
& 50 & 1.38 & 28.27 \\
Phenanthrene & 5 & 0.79 & 181.11 \\
& 50 & 8.88 & 207.10 \\
Naphthalene & 5 & 0.22 & 44.64 \\
& 50 & 7.61 & 173.32 \\
4-Chloroaniline & 5 & 0.97 & 228.85 \\
& 50 & 9.22 & 216.27 \\
& 5 & 0.82 & 189.01 \\
& 50 & 7.44 & 169.00 \\
& 5 & 0.77 & 174.76 \\
& 50 & & 200.36 \\
\hline
\end{tabular}

\subsection{Adsorption Capacity}

In order to evaluate the static uptake capacity of coumarin on the SG-1,10-PhenanNTf $f_{2}$ phase, different desired concentrations of coumarin ranging from 0 to 200 $\mathrm{mg} \cdot \mathrm{L}^{-1}$ in $25 \mathrm{~mL}$ sample solutions were mixed with 20 mg SG-1,10-PhenanNTf 2 . All these mixtures were mechanically shaken for a period of $1 \mathrm{~h}$ at room temperature, and the amount of coumarin adsorbed at each concentration level was determined. The adsorption profile of coumarin on $20 \mathrm{mg} \mathrm{SG}-1,10-\mathrm{PhenanNTf}_{2}$ was obtained by plotting the coumarin concentration $\left(\mathrm{mg} \cdot \mathrm{L}^{-1}\right)$ versus milligrams of coumarin adsorbed per gram SG-1,10PhenanNTf $_{2}$ (Figure 2). From adsorption isotherm study, the adsorption capacity of SG-1,10-PhenanNTf ${ }_{2}$ for coumarin was determined to be $85.29 \mathrm{mg} \cdot \mathrm{g}^{-1}$ (Figure 2), which is the greatest adsorption capacity reached in com- parison with adsorption capacity values previously reported for coumarin with other adsorbents $(7.17,10.56$ and $10.64 \mathrm{mg} \cdot \mathrm{g}^{-1}$ ) [14]. For comparison with the coumarin adsorption capacity of SG-1,10-PhenanNTf 2 , the coumarin uptake capacity on activated SG was also determined under the same batch conditions (Figure 2). As shown in Figure 2, the adsorption capacity of activated SG for coumarin was found to be $52.54 \mathrm{mg} \cdot \mathrm{g}^{-1}$. These results showed that the adsorption capacity for coumarin was improved by $62.33 \%$ with the modified SG-1,10PhenanNTf 2 phase.

\subsection{Adsorption Isotherm Models}

The adsorption isotherms represent the relationship between the amount adsorbed by a unit weight of adsorbent and the amount of adsorbate remaining in the solution at equilibrium. Data collected from adsorption isotherm experiments of coumarin with the SG-1,10-PhenanNTf 2 phase were evaluated by different isotherms models in order to develop an equation, which accurately represents the results $[40,41]$. The Langmuir isotherm model assumes a monolayer adsorption onto a surface containing a finite number of adsorption sites of uniform strategies of adsorption with no transmigration of adsorbate in the plane of surface, and it is given by the following equation:

$$
C_{e} / q_{e}=\left(C_{e} / Q_{o}\right)+1 / Q_{o} b
$$

where $C_{e}$ is the equilibrium concentration of coumarin $\left(\mathrm{mg} \cdot \mathrm{L}^{-1}\right), q_{e}$ and $Q_{o}$ represent the equilibrium amount and maximum amount of coumarin adsorbed per unit mass of adsorbate $\left(\mathrm{mg} \cdot \mathrm{g}^{-1}\right)$, respectively, and $\mathrm{b}$ denotes the Langmuir constant related to the rate of adsorption. Based on the least square fit, adsorption isotherm data were well fit with the Langmuir model (Figure 3). As illustrated in Figure 3, a linear plot with correlationcoefficient $\left(R^{2}\right)$ value of 0.993 was obtained from Langmuir isotherm equation when plotting $C_{e} / q_{e}$ against $C_{e}$ with a slope and intercept equal to $1 / Q_{o}$ and $1 / Q_{o} b$, respectively. Consequently, adsorption isotherm data provided that the adsorption process was mainly monolayer on a homogeneous adsorbent surface. The Langmuir constants $Q_{o}$ and $b$ were found to be $88.77 \mathrm{mg} \cdot \mathrm{g}^{-1}$ and $0.13 \mathrm{~L} \cdot \mathrm{mg}^{-1}$, respectively. It is also interesting to note that the coumarin adsorption capacity $\left(88.77 \mathrm{mg} \cdot \mathrm{g}^{-1}\right)$ calculated from Langmuir equation was closely associated with that $(85.29$ $\mathrm{mg} \cdot \mathrm{g}^{-1}$ ) experimentally obtained from the isotherm study. The effect of the isotherm shape has been discussed with a view to predict whether an adsorption system is favorable or unfavorable. The essential feature of the Langmuir isotherm can be expressed by means of a dimensionless constant separation factor or equilibrium parameter $\left(R_{L}\right) . R_{L}$ is calculated using the following equation: 


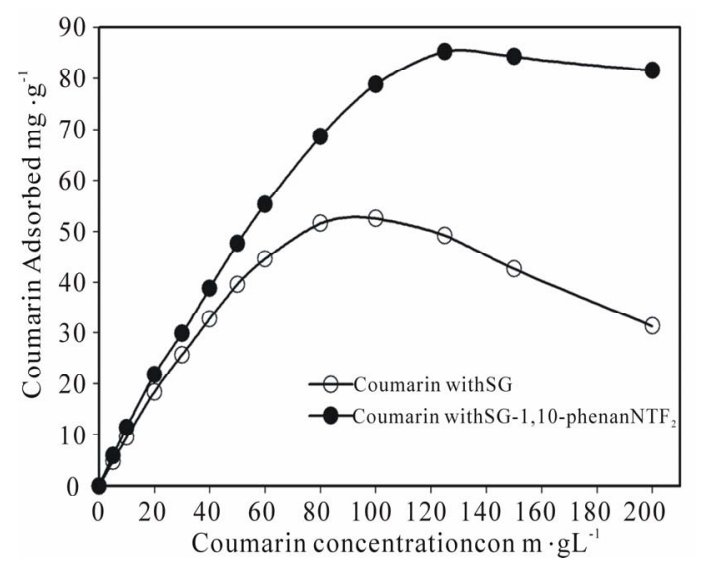

Figure 2. Adsorption isotherm of coumarin on 20 activated SG and SG-1,10-PhenanNTf $\mathrm{f}_{2}$ phase in relation to the concentration at $25^{\circ} \mathrm{C}$.

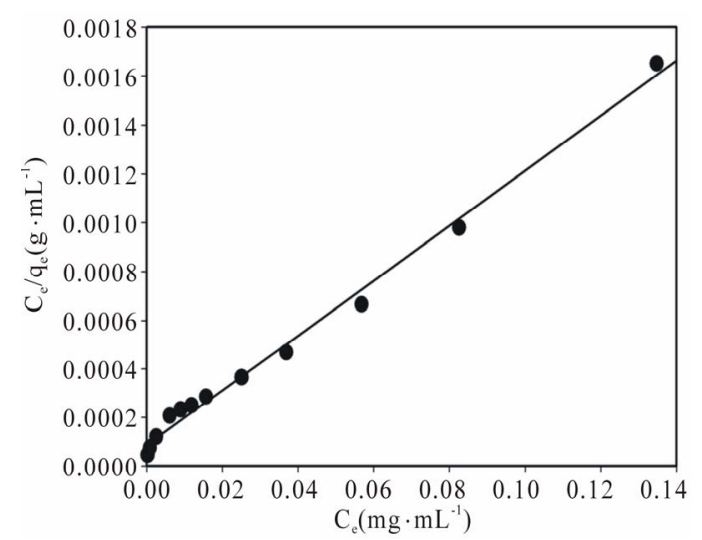

Figure 3. Langmuir adsorption isotherm model of coumarin adsorption on $20 \mathrm{mg} \mathrm{SG}-1,10-P h e n a n N T f_{2}$ at $25^{\circ} \mathrm{C}$. Adsorption experiments were obtained at different concentrations $\left(0-200 \mathrm{mg} \cdot \mathrm{L}^{-1}\right)$ of coumarin under batch conditions.

$$
R_{L}=1 /\left(1+b C_{o}\right)
$$

where $b$ is the Langmuir constant which indicates the nature of adsorption and the shape of the isotherm, and $C_{o}$ refers to the initial coumarin concentration $\left(\mathrm{mg} \cdot \mathrm{L}^{-1}\right)$. The $R_{L}$ value indicates the type of the isotherm, and $R_{L}$ values lying between 0 and 1 provided that the conditions were favorable for adsorption [42]. The $R_{L}$ value of coumarin adsorption on SG-1,10-PhenanNTf $\mathrm{N}_{2}$ was estimated to be 0.05 , confirming that the adsorption is strongly favorable under conditions used in this study. Thus, adsorption data indicated the formation of monolayer on a homogeneous adsorbent surface with a highly favorable adsorption process based on the Langmuir adsorption isotherm model.

\subsection{Effect of Shaking Time}

The effect of shaking time is one of the most important factors when using the batch technique in processes of the adsorption capacity determination for organic compounds. In this study, different shaking times were chosen, ranging from 2.5 to $60.0 \mathrm{~min}$, in order to study the behavior of adsorption kinetics for coumarin on the SG1,10 -PhenanNTf $f_{2}$ phase. Based on the results, it was observed that equilibrium kinetics were very fast. As displayed in Figure 4, an amount of $67.56 \mathrm{mg} \cdot \mathrm{g}^{-1}$ coumarin was adsorbed on SG-1,10-PhenanNTf $f_{2}$ after only 20 min of the equilibrium period. Then, the amount of coumarin adsorbed was raised up to $76.53 \mathrm{mg} \cdot \mathrm{g}^{-1}$ after $40 \mathrm{~min}$ until the maximum adsorption of SG-1,10-PhenanNTf $\mathrm{N}_{2}$ for coumarin was reached to $85.29 \mathrm{mg} \cdot \mathrm{g}^{-1}$ after $60 \mathrm{~min}$.

\subsection{Kinetic Models}

Different kinetic models were also investigated in order to find intrinsic kinetic adsorption parameters for explaining the nature of adsorption process. Kinetic models were used for goodness of fit for experimental data using the correlation coefficient $\left(R^{2}\right)$ as a measure of convention between experimental data. The adsorption kinetic equation of a pseudo second-order adsorption is expressed as follows:

$$
t / q_{t}=1 / v_{o}+\left(1 / q_{e}\right) t
$$

where $v_{o}=k_{2} q_{e}^{2}$ is the initial adsorption rate $\left(\mathrm{mg} \cdot \mathrm{g}^{-1}\right.$. $\left.\min ^{-1}\right)$ and $k_{2}\left(\mathrm{~g} \cdot \mathrm{mg}^{-1} \cdot \mathrm{min}^{-1}\right)$ corresponds to the rate constant of adsorption, $q_{e}\left(\mathrm{mg} \cdot \mathrm{g}^{-1}\right)$ denotes the amount of compound adsorbed at equilibrium, and $q_{t}\left(\mathrm{mg} \cdot \mathrm{g}^{-1}\right)$ refers to the amount of compound on the adsorbent surface at any time $t(\mathrm{~min})$. The parameters $q_{e}$ and $v_{o}$ can be obtained from the slope and intercept, respectively, of a plot of $t / q_{t}$ versus $t$ [43]. The kinetic parameters $q_{e}$ and $v_{o}$ were calculated from the slope and intercept, respectively, of the linear plots of $t / q_{t}$ versus $t$, as shown in Figure 5. The correlation coefficient $\left(R^{2}\right)$ factor was found to be 0.997 , providing that the pseudo second-order adsorption is more reliable and accurate. The parameters $q_{e}, v_{o}$ and $k_{2}$ were determined to be $92.72 \mathrm{mg} \cdot \mathrm{g}^{-1}, 11.61 \mathrm{mg} \cdot \mathrm{g}^{-1} \cdot \mathrm{min}^{-1}$ and $0.0013 \mathrm{~g} \cdot \mathrm{mg}^{-1} \cdot \mathrm{min}^{-1}$, respectively. The coumarin adsorption capacity on SG-1,10-PhenanNTf $\mathrm{N}_{2}$ obtained from the pseudo second-order kinetic model $\left(92.72 \mathrm{mg} \cdot \mathrm{g}^{-1}\right)$ was also in good agreement with adsorption capacities obtained from adsorption isotherm experiments (85.29 $\left.\mathrm{mg} \cdot \mathrm{g}^{-1}\right)$ and from the Langmuir isotherm model $(88.77$ $\left.\mathrm{mg} \cdot \mathrm{g}^{-1}\right)$, supporting the highest applicability of the pseudo second-order nature of the adsorption of coumarin by SG-1,10-PhenanNTf . $_{\text {. }}$

\subsection{Performance of Method in Analytical Applications}

\subsubsection{Effect of Matrix Interferences}

In order to evaluate the possibility of analytical applications for the proposed procedure in analyzing real samples, the effect of several compounds was investigated 


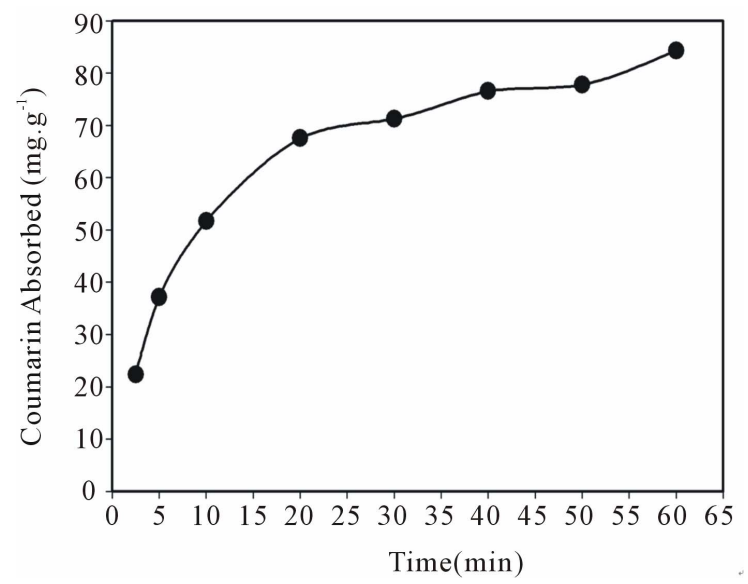

Figure 4. Effect of shaking time on coumarin uptake using $20 \mathrm{mg} \mathrm{SG}-1,10-\mathrm{PhenanNTf}_{2}$ phase at $25^{\circ} \mathrm{C}$.

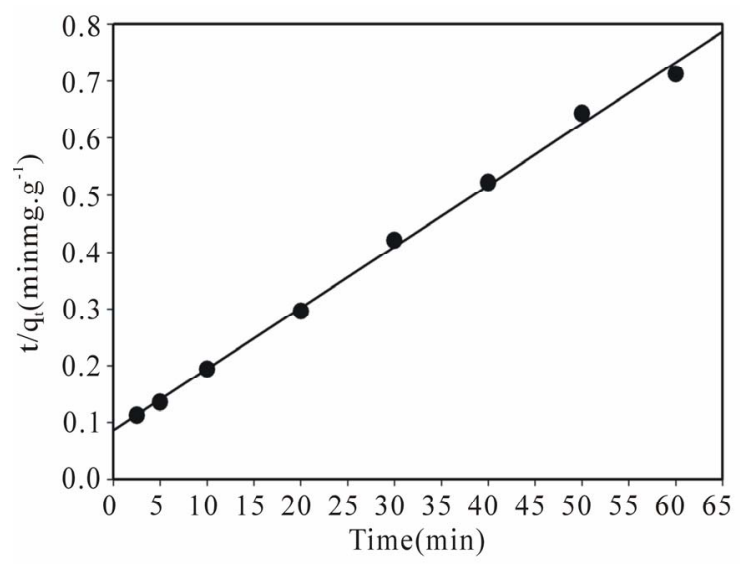

Figure 5. Pseudo second-order adsorption kinetic model of coumarin uptake on $20 \mathrm{mg} \mathrm{SG}-1,10-$ PhenanNTf $_{2}$ at $25^{\circ} \mathrm{C}$.

under optimized conditions. A model standard solution containing fixed amount of $150 \mathrm{mg} \cdot \mathrm{L}^{-1}$ coumarin with mixed matrix compounds, including $150 \mathrm{mg} \cdot \mathrm{L}^{-1}$ flavone, naphthalene and phenanthrene, was treated according to the recommended procedure. As shown in Figure 6, it can be clearly observed that coumarin was retained more than other compounds, providing that the SG-1,10-PhenanNTf ${ }_{2}$ adsorbent was most selective toward coumarin. Calculated uptake capacity and distribution coefficient values are reported in Table 2 for each compound adsorbed on the SG-1,10-PhenanNTf $\mathrm{f}_{2}$ phase in this mixed matrix. As displayed in Table 2, coumarin had the largest static uptake capacity, $q_{e},\left(76.38 \mathrm{mg} \cdot \mathrm{g}^{-1}\right)$ and distribution coefficient, $K_{d}$, value up to $859.11 \mathrm{~mL} \cdot \mathrm{g}^{-1}$ on the $\mathrm{SG}-1$, 10-PhenanNTf $f_{2}$ adsorbent as compared with other compounds in the mixed matrix. The effect of medium composition containing mixed compounds has, therefore, no significant influence on the extraction of coumarin. Thus, the selectivity of the proposed method is high enough to be applied to the determination of coumarin in real samples.

\subsubsection{Application of the Proposed Method}

In order to establish the validity of the proposed procedure, the method was applied to the determination of coumarin in real water samples. A standard addition method was performed under the same batch conditions to estimate the accuracy of the extraction of coumarin. An amount of 5, 10 or $20 \mathrm{mg} \cdot \mathrm{L}^{-1}$ coumarin was spiked in three different types of water samples, including ground water, lake water and waste water, collected from Jeddah in Saudi Arabia. The \% extraction of each amount of coumarin in real water samples was calculated, and the results are summarized in Table 3. As can be observed in Table 3, the \% extraction of coumarin in real water samples was reasonable, in the range of $85.02 \%$ - $94.39 \%$. In addition, it is interesting to note that the unadsorbed fraction of coumarin was largely decreased when the added fraction was increased to $20 \mathrm{mg} \cdot \mathrm{L}^{-1}$. In fact, this behavior can be ascribed to the low adsorption capacity or rate for interfering chemical species presented in real water samples toward the SG-1,10-PhenanNTf 2 phase. Thus, results suggested that the extraction of coumarin in spiked water samples was satisfactory for trace analysis and apparently demonstrated that the method is reliable, feasible and suitable for analyzing real samples.

\section{Conclusion}

It can be concluded from the results that SG-1,10-PhenanNTf $f_{2}$ is an effective adsorbent for selective extraction and determination of trace levels of coumarin at short contact time. Adsorption isotherm data of coumarin adsorption on SG-1,10-PhenanNTf $f_{2}$ were well fit with Langmuir adsorption isotherm model, providing that the adsorption process was mainly monolayer onto a homogeneous adsorbent surface. Results also demonstrated that the adsorption of coumarin on the SG-1,10-Phenan$\mathrm{NTf}_{2}$ phase obeyed a pseudo second-order kinetic model. Moreover, the extraction of coumarin by the SG-1,10PhenanNTf $f_{2}$ was not affected by the medium composition containing mixed compounds. The proposed method ultimately afforded acceptable and reliable results for a selective adsorption and determination of coumarin in real

Table 2. Effect of matrix interferences on the extraction of $150 \mathrm{mg} \cdot \mathrm{L}^{-1}$ coumarin on $20 \mathrm{mg} \mathrm{SG}-1,10-$ PhenanNTf $\mathrm{f}_{2}(\mathrm{~N}=$ 3).

\begin{tabular}{cccc}
\hline Compound & $\begin{array}{c}\text { Concentration } \\
\left(\mathrm{mg} \cdot \mathrm{L}^{-1}\right)\end{array}$ & $\begin{array}{c}q_{e} \\
\left(\mathrm{mg} \cdot \mathrm{g}^{-1}\right)\end{array}$ & $\begin{array}{c}K_{d} \\
\left(\mathrm{~mL} \cdot \mathrm{g}^{-1}\right)\end{array}$ \\
\hline Coumarin & 150 & 76.38 & 859.11 \\
Flavone & 150 & 6.68 & 46.20 \\
Phenanthrene & 150 & 2.31 & 15.62 \\
Naphthalene & 150 & 7.91 & 55.08 \\
\hline
\end{tabular}


Table 3. Determination of coumarin at different concentrations $\left(5,10\right.$ and $\left.20 \mathrm{mg} \cdot \mathrm{L}^{-1}\right)$ in real water samples using 20 mg SG-1,10-PhenanNTf $(\mathbf{N}=3)$.

\begin{tabular}{cccc}
\hline Samples & $\begin{array}{c}\text { Added } \\
\left(\mathrm{mg} \cdot \mathrm{L}^{-1}\right)\end{array}$ & $\begin{array}{c}\text { Unadsorbed } \\
\left(\mathrm{mg} \cdot \mathrm{L}^{-1}\right)\end{array}$ & $\begin{array}{c}\text { Extraction } \\
(\%)\end{array}$ \\
\hline \multirow{3}{*}{ Ground water } & 5 & 0.33 & 93.38 \\
& 10 & 0.97 & 90.30 \\
Lake water & 20 & 2.70 & 86.50 \\
& 5 & 0.28 & 94.39 \\
Waste water & 10 & 0.88 & 91.21 \\
& 5 & 2.60 & 87.00 \\
& 10 & 0.35 & 92.96 \\
& 20 & 0.99 & 90.11 \\
\end{tabular}

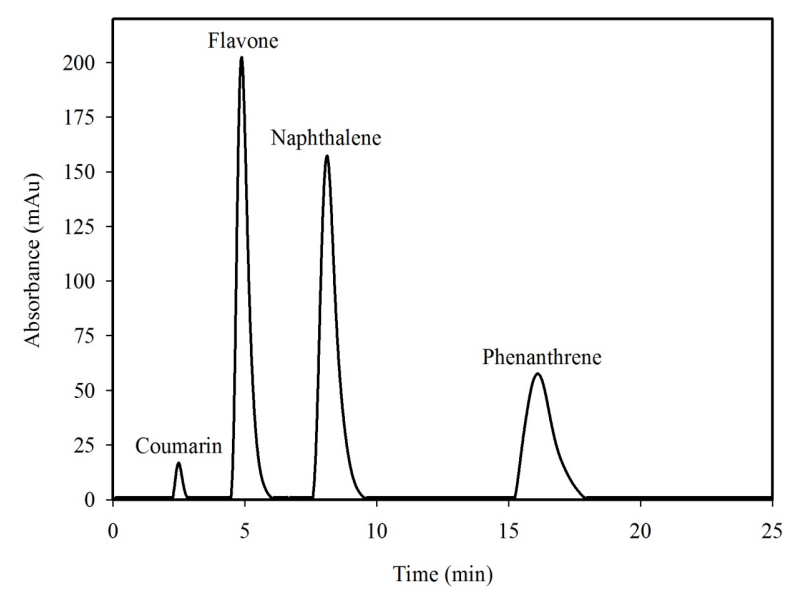

Figure 6. Effect of matrix interferences on the extraction of coumarin by $20 \mathrm{mg} \mathrm{SG}-1,10-$ PhenanNTf $_{2}$ at $25^{\circ} \mathrm{C}$. Adsorption experiments were performed with $150 \mathrm{mg} \cdot \mathrm{L}^{-1} \mathrm{cou}-$ marin, flavone, naphthalene and phenanthrene mixture under batch conditions.

water samples with complicated and variable matrices.

\section{Acknowledgements}

The authors gratefully acknowledge the Department of Chemistry and Center of Excellence for Advanced Materials Research at King Abdulaziz University for providing research facilities.

\section{REFERENCES}

[1] M. Ahnoff and B. Josefsson, "Simple Apparatus for on-Site Continuous Liquid-Liquid Extraction of Organic Compounds from Natural Waters," Analytical Chemistry, Vol. 46, No. 6, 1974, pp. 658-663. doi:10.1021/ac60342a025

[2] S. Nishihama, T. Hirai and I. Komasawa, "Review of Advanced Liquid-Liquid Extraction Systems for the Separation of Metal Ions by a Combination of Conversion of the Metal Species with Chemical Reaction," Industrial \& Engineering Chemistry Research, Vol. 40, No. 14, 2001, pp. 3085-3091. doi:10.1021/ie010022+
[3] M. R. Pourjavid, P. Norouzi and M. R. Ganjali, "Light Lanthanides Determination by Fast Fourier Transform Continuous Cyclic Voltammetry after Separation by IonExchange Chromatography," International Journal of Electrochemical Science, Vol. 4, No. 7, 2009, pp. 923942.

[4] X. Xue, J. Zhao, L. Chen, J. Zhou, B. Yue, Y. Li, L. Wu and F. Liu, "Analysis of Coenzyme Q10 in Bee Pollen Using Online Cleanup by Accelerated Solvent Extraction and High Performance Liquid Chromatography," Food Chemistry, Vol. 133, No. 2, 2012, pp. 573-578. doi:10.1016/j.foodchem.2011.12.085

[5] S. Zhong, S. N. Tan, L. Ge, W. Wang and J. Chen, "Determination of Bisphenol A and Naphthols in River Water Samples by Capillary Zone Electrophoresis after Cloud Point Extraction," Talanta, Vol. 85, No. 1, 2011, pp. 488492. doi:10.1016/i.talanta.2011.04.009

[6] W.-L. Liu, B.-H. Hwang, Z.-G. Li, J.-F. Jen and M.-R. Lee, "Headspace Solid Phase Microextraction in-Situ Supercritical Fluid Extraction Coupled to Gas Chromatography_-Tandem Mass Spectrometry for Simultaneous Determination of Perfluorocarboxylic Acids in Sediments," Journal of Chromatography A, Vol. 1218, No. 43, 2011, pp. 7857-7863. doi:10.1016/j.chroma.2011.08.062

[7] I. Liška, "Fifty Years of Solid-Phase Extraction in Water Analysis Historical Development and Overview," Journal of Chromatography A, Vol. 885, No. 1-2, 2000, pp. 3-16. doi:10.1016/S0021-9673(99)01144-9

[8] L. M. Ravelo-Perez, A. V. Herrera-Herrera, J. HernandezBorges and M. A. Rodriguez-Delgado, "Carbon Nanotubes: Solid-Phase Extraction," Journal of Chromatography $A$, Vol. 1217, No. 16, 2010, pp. 2618-2641. doi:10.1016/j.chroma.2009.10.083

[9] S. Sadeghi and E. Sheikhzadeh, "Solid Phase Extraction Using Silica Gel Modified with Murexide for Preconcentration of Uranium (VI) Ions from Water Samples," Journal of Hazardous Materials, Vol. 163, No. 2-3, 2009, pp. 861-868. doi:10.1016/j.jhazmat.2008.07.053

[10] A. Afkhami, T. Madrakian, R. Ahmadi, H. Bagheri and M. Tabatabaee, "Chemically Modified Alumina Nanoparticles for Selective Solid Phase Extraction and Preconcentration of Trace Amounts of Cd(II)," Microchimica Acta, Vol. 175, No. 1-2, 2011, pp. 69-77. doi:10.1007/s00604-011-0660-x

[11] Z. Li, X. Chang, Z. Hu, X. Huang, X. Zou, Q. Wu and R. Nie, "Zincon-Modified Activated Carbon for Solid-Phase Extraction and Preconcentration of Trace Lead and Chromium from Environmental Samples," Journal of Hazardous Materials, Vol. 166, No. 1, 2009, pp. 133-137. doi:10.1016/j.jhazmat.2008.11.006

[12] F. M. de Oliveira, B. F. Somera, M. Z. Corazza, M. J. S. Yabe, M. G. Segatelli, E. S. Ribeiro, E. C. Lima, S. L. P. Dias and C. R. T. Tarley, "Cellulose Microfiber Functionalized with N,N'-Bis (2-Aminoethyl)-1,2-Ethanediamine as a Solid Sorbent for the Fast Preconcentration of Cd(II) in Flow System Analysis," Talanta, Vol. 85, No. 5, 2011, pp. 2417-2424. doi:10.1016/j.talanta.2011.07.088

[13] Y. Li, X. Xie, M. L. Lee and J. Chen, "Preparation and Evaluation of Hydrophilic C18 Monolithic Sorbents for Enhanced Polar Compound Retention in Liquid Chroma- 
tography and Solid Phase Extraction," Journal of Chromatography A, Vol. 1218, No. 48, 2011, pp. 8608-8616. doi:10.1016/j.chroma.2011.09.070

[14] Z. Wei, Y. Zu, Y. Fu, W. Wang, C. Zhao, M. Luo and T. Efferth, "Resin Adsorption as a Means to Enrich Rare Stilbenes and Coumarin from Pigeon Pea Leaves Extracts," Chemical Engineering Journal, Vol. 172, No. 2-3, 2011, pp. 864-871. doi:10.1016/j.cej.2011.06.075

[15] H. Zeng, Y. Wang, X. Liu, J. Kong and C. Nie, "Preparation of Molecular Imprinted Polymers Using Bi-Functional Monomer and Bi-Crosslinker for Solid-Phase Extraction of Rutin," Talanta, Vol. 93, 2012, pp. 172-181. doi:10.1016/j.talanta.2012.02.008

[16] R. K. Dey, F. J. V. E. Oliveira and C. Airoldi, "Mesoporous Silica Functionalized with Diethylenetriamine Moieties for Metal Removal and Thermodynamics of CationBasic Center Interactions," Colloids and Surfaces A: Physicochemical and Engineering Aspects, Vol. 324, No. 1-3, 2008, pp. 41-46. doi:10.1016/j.colsurfa.2008.03.030

[17] L. Zhang, X. Chang, Y. Zhai, Q. He, X. Huang, Z. Hu and N. Jiang, "Selective Solid Phase Extraction of Trace Sc(III) from Environmental Samples Using Silica Gel Modified with 4-(2-Morinyldiazenyl)- $N$-(3-(Tri-methylsilyl)Propyl)Benzamide," Analytica Chimica Acta, Vol. 629, No. 1-2, 2008, pp. 84-91. doi:10.1016/j.aca.2008.09.039

[18] Z. Wei, L. Wang, J. Li, X. Liu and S. Jiang, "Cyanobiphenyl-Mesogened Liquid Crystalline Polymer Bonded on Silica as the Stationary Phase with Shape and Polarity Recognition for LC," Chromatographia, Vol. 73, No. 1-2, 2011, pp. 5-16. doi:10.1007/s10337-010-1834-0

[19] M. Ghaedi and E. Sharifpour, "Chemically Modified Nano Silica Gel with 2-((3silylpropylimino) Methyl)-2-Hydroxy1-Naphthol (SPIMHN) as Good and Efficient Adsorbent for Solid Phase Extraction," Desalination and Water Treatment, Vol. 41, No. 1-3, 2012, pp. 315-324. doi:10.1080/19443994.2012.664720

[20] J. Fan, C. Wu, Y. Wei, C. Peng and P. Peng, "Preparation of Xylenol Orange Functionalized Silica Gel as a Selective Solid Phase Extractor and Its Application for Preconcentration-Separation of Mercury from Waters," Journal of Hazardous Materials, Vol. 145, No. 1-2, 2007, pp. 323-330. doi:10.1016/i.jhazmat.2006.11.025

[21] T. Welton, "Room-Temperature Ionic Liquids. Solvents for Synthesis and Catalysis," Chemical Reviews, Vol. 99, No. 8, 1999, pp. 2071-2083. doi:10.1021/cr980032t

[22] G.-T. Wei, Z. Yang and C.-J. Chen, "Room Temperature Ionic Liquid as a Novel Medium for Liquid/Liquid Extraction of Metal Ions," Analytica Chimica Acta, Vol. 488, No. 2, 2003, pp. 183-192. doi:10.1016/S0003-2670(03)00660-3

[23] H. Zhao, S. Xia and P. Ma, "Use of Ionic Liquids as 'Green' Solvents for Extractions," Journal of Chemical Technology and Biotechnology, Vol. 80, No. 10, 2005, pp. 1089-1096. doi:10.1002/jctb.1333

[24] C. F. Poole and S. K. Poole, "Extraction of Organic Compounds with Room Temperature Ionic Liquids," Journal of Chromatography A, Vol. 1217, No. 16, 2010, pp. 2268-2286. doi:10.1016/j.chroma.2009.09.011
[25] A. E. Visser, R. P. Swatloski, S. T. Griffin, D. H. Hartman and R. D. Rogers, "Liquid/Liquid Extraction of Metal Ions in Room Temperature Ionic Liquids," Separation Science and Technology, Vol. 36, No. 5-6, 2001, pp. 785-804. doi:10.1081/SS-100103620

[26] F. van Rantwijk, R. Madeira Lau and R. A. Sheldon, "Biocatalytic Transformations in Ionic Liquids," Trends in Biotechnology, Vol. 21, No. 3, 2003, pp. 131-138. doi:10.1016/S0167-7799(03)00008-8

[27] W. L. Hough, M. Smiglak, H. Rodriguez, R. P. Swatloski, S. K. Spear, D. T. Daly, J. Pernak, J. E. Grisel, R. D. Carliss, M. D. Soutullo, J. H. J. Davis and R. D. Rogers, "The Third Evolution of Ionic Liquids: Active Pharmaceutical Ingredients," New Journal of Chemistry, Vol. 31, No. 8, 2007, pp. 1429-1436. doi:10.1039/b706677p

[28] J.-F. Liu, G.-B. Jiang, J.-F. Liu and J. Å. Jönsson, “Application of Ionic Liquids in Analytical Chemistry," Trends in Analytical Chemistry, Vol. 24, No. 1, 2005, pp. 20-27. doi:10.1016/j.trac.2004.09.005

[29] F. Fabregat-Santiago, J. Bisquert, E. Palomares, L. Otero, D. Kuang, S. M. Zakeeruddin and M. Gratzel, "Correlation between Photovoltaic Performance and Impedance Spectroscopy of Dye-Sensitized Solar Cells Based on Ionic Liquids," The Journal of Physical Chemistry C, Vol. 111, 2007, pp. 6550-6560. doi:10.1021/jp066178a

[30] P. Wang, S. M. Zakeeruddin, P. Comte, I. Exnar and M. Gratzel, "Gelation of Ionic Liquid-Based Electrolytes with Silica Nanoparticles for Quasi-Solid-State Dye-Sensitized Solar Cells," Journal of the American Chemical Society, Vol. 125, No. 5, 2003, pp. 1166-1167. doi:10.1021/ja029294+

[31] L. Yu, D. Garcia, R. Ren and X. Zeng, "Ionic Liquid High Temperature Gas Sensors," Chemical Communications, No. 17, 2005, pp. 2277-2279.

[32] D. Han, M. Tian, D. W. Park, D. K. Choi and K. H. Row, "Application of Ionic Liquids as Mobile Phase Additives and Surface-Bonded Stationary Phase in Liquid Chromatography," Korean Journal of Chemical Engineering, Vol. 26, No. 5, 2009, pp. 1353-1358. doi:10.1007/s11814-009-0209-4

[33] A. Berthod, M. J. Ruiz-Angel and S. Carda-Broch, "Ionic Liquids in Separation Techniques," Journal of Chromatography A, Vol. 1184, No. 1-2, 2008, pp. 6-18. doi:10.1016/j.chroma.2007.11.109

[34] M. E. Mahmoud and H. M. Al-Bishri, "Supported Hydrophobic Ionic Liquid on Nano-Silica for Adsorption of Lead," Chemical Engineering Journal, Vol. 166, No. 1, 2011, pp. 157-167. doi:10.1016/j.cej.2010.10.046

[35] G. Fang, J. Chen, J. Wang, J. He and S. Wang, "N-Methylimidazolium Ionic Liquid-Functionalized Silica as a Sorbent for Selective Solid-Phase Extraction of 12 Sulfonylurea Herbicides in Environmental Water and Soil Samples," Journal of Chromatography A, Vol. 1217, No. 10, 2010, pp. 1567-1574 doi:10.1016/j.chroma.2010.01.010

[36] L. Vidal, J. Parshintsev, K. Hartonen, A. Canals and M.-L. Riekkola, "Ionic Liquid-Functionalized Silica for Selective Solid-Phase Extraction of Organic Acids, Amines and Aldehydes," Journal of Chromatography A, Vol. 
1226, 2012, pp. 2-10. doi:10.1016/j.chroma.2011.08.075

[37] H. M. Marwani, "Selective Separation and Determination of Lead Based on Silica Gel Developed by Surface Adsorbed New Hydrophobic Ionic Liquid," Journal of Dispersion Science and Technology, Vol. 34, No. 1, 2013, pp. 117-124. doi:10.1080/01932691.2011.653925

[38] H. M. Marwani, "Spectroscopic Evaluation of Chiral and Achiral Fluorescent Ionic Liquids," Central European Journal of Chemistry, Vol. 8, No. 4, 2010, pp. 946-952. doi:10.2478/s11532-010-0062-7

[39] D. M. Han, G. Z. Fang and X. P. Yan, "Preparation and Evaluation of a Molecularly Imprinted Sol-Gel Material for on-Line Solid-Phase Extraction Coupled with High Performance Liquid Chromatography for the Determination of Trace Pentachlorophenol in Water Samples," Journal of Chromatography A, Vol. 1100, No. 2, 2005, pp. 131-136. doi:10.1016/i.chroma.2005.09.035
[40] H. Freundlich, "ÜBer Die Adsorption in LöSungen (Adsorption in Solution)," Zeitschrift für Physikalische Chemie, Vol. 57, 1906, pp. 384-470.

[41] I. Langmuir, "The Constitution and Fundamental Properties of Solids and Liquids," Journal of the American Chemical Society, Vol. 38, No. 11, 1916, pp. 2221-2295. doi: $10.1021 / \mathrm{ja} 02268 \mathrm{a} 002$

[42] G. Mckay, H. S. Blair and J. R. Gardener, "Adsorption of Dyes on Chitin-I: Equilibrium Studies," Journal of Applied Polymer Science, Vol. 27, No. 8, 1982, pp. 30433057. doi:10.1002/app.1982.070270827

[43] Y. Ho, "Second-Order Kinetic Model for the Sorption of Cadmium onto Tree Fern: A Comparison of Linear and Non-Linear Methods," Water Research, Vol. 40, No. 1, 2006, pp. 119-125. doi:10.1016/j.watres.2005.10.040 